\title{
Digestibilidade parcial e total de rações com a inclusão de ionóforo ou probiótico para bubalinos e bovinos ${ }^{1}$
}

\author{
Lucia Maria Zeoula², Juliano Ricardo Fontanini Beleze ${ }^{3}$, Luiz Juliano Valério Geron ${ }^{3}$, Emilyn \\ Midori Maeda ${ }^{3}$, Ivanor Nunes do Prado ${ }^{2}$, Meiby Carneiro de Paula ${ }^{3}$
}

\footnotetext{
1 Projeto financiado pelo Conselho Nacional de Desenvolvimento Científico e Tecnológico - CNPq.

2 Departamento de Zootecnia - UEM - Av. Colombo, 5790. CEP: 87020-900, Maringá-PR. Pesquisador do CNPq.

3 Pós-graduação em Zootecnia - UEM - Av. Colombo, 5790. CEP: 87020-900, Maringá-PR.
}

\begin{abstract}
RESUMO - Avaliaram-se os efeitos do ionóforo (monensina sódica) e do probiótico (Saccharomyces cerevisiae + selênio + cromo) em rações com 50:50\% de volumoso:concentrado sobre os coeficientes de digestibilidade total (CDT) e parcial dos nutrientes. Foram utilizados três búfalos da raça Murrah e três bovinos da raça holandesa, com peso médio de $477 \pm 47$ e $518 \pm 56$ kg, respectivamente, portadores de cânula ruminal e duodenal, distribuídos em delineamento experimental com dois quadrados latinos $3 \times 3$ e arranjo fatorial $3 \times 2$. O indicador dos fluxos fecal e duodenal foi a cinza insolúvel em ácido. Não houve interação dieta $\times$ espécie animal para os CTD dos nutrientes, porém a adição de ionóforo à ração teve efeito positivo sobre os CDT de MS, PB, EE e amido e a adição de probiótico aumentou os CDT do amido, da FDN e da FDA. As adições de ionóforo e probiótico propiciaram maior fermentação ruminal da FDN e FDA e maiores coeficientes de digestibilidade intestinal (CDI) do amido. Observaram-se maiores CDT da PB e do amido para os bovinos e maior CDT da FDN para búfalos. Houve interação rações $\times$ espécie somente sobre os coeficientes de digestibilidade ruminal (CDR) e CDI de MS, PB e EE. Para ambas as espécies, a adição de ionóforo foi efetiva em aumentar a fermentação ruminal da MS, reduzir a degradação ruminal da PB e elevar o CDI da PB. A adição do probiótico também reduziu a degradação ruminal da PB em bubalinos, porém em menor escala que o ionóforo. Independentemente da presença ou não dos aditivos nas rações, os bubalinos apresentaram maior CDR da MS e sem a adição de aditivos, maior CDR da PB e menor CDI da PB que os bovinos.
\end{abstract}

Palavras-chave: aditivo, monensina sódica, bovídeos, Saccharomyces cerevisiae

\section{Total and partial digestibility of diets with ionophore or probiotic inclusion for buffaloes and bovine}

\begin{abstract}
The effects of the ionophore (sodic monensin) and of the probiotic (Saccharomyces cerevisiae + selenium + chrome) were evaluated in rations with 50:50\% of forage:concentrate ratio on the total (TDC) and partial [ruminal digestibility coefficients (RDC) and intestinal (IDN)] nutrients digestibility coefficients. Three Murrah buffalos (Bubalus bubalis) and three steers Holstein (Bos taurus), with an of $477 \pm 47 \mathrm{~kg}$ and $518 \pm 56 \mathrm{~kg}$ of average weight respectively, and with ruminal and duodenal cannulas were used; the animals were designed into two $3 \times 3$ latin squares and in a $3 \times 2$ factorial arrangement. The acid insoluble ash was the internal marker for fecal and duodenal flow. No interaction of diet and animal species for TDC of nutrients was observed, although the ionophore addition in the ration showed a positive effect on TDC for DM, CP, EE and starch and the probiotic addition increased TDC of starch, NDF and ADF. The ionophore and probiotic addition provided higher ruminal fermentation of NDF and ADF and higher IDC of starch. It was observed higher TDC of CP and starch for bovine and higher TDC of NDF for buffaloes. There was interaction of rations $\times$ species only on RDC and IDC for DM, CP and EE. The ionophore addition was effective to increase the ruminal fermentation of DM, to reduce rumina degradation of CP and to increase IDC of CP for both species. The probiotic addition also reduces ruminal degradation of CP in buffaloes, but in lower scale than ionophore. For buffaloes, the presence or absence of additives in rations caused higher RDC of DM, the absence of addictives in ration caused higher RDC and lower IDC of CP than in bovine.
\end{abstract}

Key Words: additive, bovideos, sodic monensin, Saccharomyces cerevisiae

\section{Introdução}

A manipulação da fermentação ruminal por meio da utilização de produtos modificadores (aditivos) é depen- dente do sistema de produção (Van Nevel, 1991). O processo de otimização da fermentação ruminal pode ser considerado como a maximização ou minimização de reações no rúmen, dependendo do tipo e do teor de alimentação, da produção 
animal e dos compostos utilizados na modificação da fermentação ruminal. Em qualquer situação, processos que devem ser maximizados são a síntese de proteína microbiana e a fermentação da fibra em ácidos graxos voláteis e os que devem ser minimizados, a metanogênese, a degradação da proteína verdadeira do alimento, a biohidrogenação de ácidos graxos insaturados e, em parte, a fermentação do amido.

O emprego de maiores quantidades de grãos de cereais na dieta de bovinos em confinamento baseia-se no fato de os mesmos serem ricos em amido, que é o principal responsável pela energia necessária para manutenção e crescimento das bactérias ruminais (Passini et al., 2003). Por sua vez, os microrganismos do rúmen, pelas vias metabólicas de extração de energia, produzem principalmente os ácidos graxos voláteis, que, segundo Van Soest (1994), suprem mais de 85\% das exigências energéticas do animal.

O ionóforo é um antibiótico que diminui o crescimento de bactérias proteolíticas e a degradação de proteína hidrolisada e dietética (Russell \& Martin, 1984). A monensina inibe principalmente bactérias gram-positivas, mas a resistência ao ionóforo está relacionada à presença de uma camada lipopolissacarídica externa à membrana celular existente em bactérias gram-negativas. A monensina tem pouco impacto na média de ganho diário do animal, contribuindo para a redução da ingestão de alimento e a razão acetato/propionato no fluído ruminal (Russell, 1996). Assim, a monensina é fornecida em dietas para animais que consomem grande quantidade de grãos, em que a economia quanto à da aquisição dos alimentos, para os grandes produtores de carne ou leite, se torna importante.

As leveduras, principalmente Saccharomyces cerevisiae, usadas na alimentação animal há várias décadas, são fontes de proteínas de alta qualidade, vitaminas do complexo B e minerais, especialmente selênio e zinco. Seu uso na alimentação de ruminantes também tem sido cogitado em pequena quantidade, como aditivo, consistindo em fator de crescimento para bactérias do rúmen, principalmente celulolíticas. Segundo Wallace (1992) e Kamalamma et al. (1996), o emprego de levedura nas dietas de ruminantes pode provocar alterações na razão acetato/propionato e ainda aumentar o fluxo de proteína microbiana para o intestino delgado.

O aumento no potencial genético dos animais demanda dietas com maiores teores energéticos e protéicos, sendo que a adição de produtos capazes de controlar ou modificar o padrão de fermentação no rúmen é uma estratégia importante. Porém, estudos devem ser realizados com estes produtos, principalmente em relação a seus efeitos ao longo dos vários compartimentos do trato digestório sobre os padrões fermentativos e absortivos em bovinos e principalmente em búfalos cujas informações são escassas nessa espécie. Assim, objetivou-se avaliar o efeito do ionóforo (monensina sódica) e do probiótico (Saccharomyces cerevisiae + selênio + cromo) em rações com 50:50\% de volumoso:concentrado sobre a digestibilidade total e parcial dos nutrientes em bubalinos e bovinos.

\section{Material e Métodos}

O experimento foi conduzido no Setor de Bovinocultura de Corte da Fazenda Experimental de Iguatemi (FEI), no período de dezembro de 2003 a fevereiro de 2004. As análises químicas foram realizadas no Laboratório de Análises de Alimentos e Nutrição Animal, pertencentes ao Departamento de Zootecnia da Universidade Estadual de Maringá.

Foram utilizados três búfalos, castrados, da raça Murrah (Bubalus bubalis) com peso vivo (PV) médio de $477 \pm 47 \mathrm{~kg}$ e três bovinos, castrados, da raça Holandesa (Bos taurus), com PV médio de $518 \pm 56$ kg, portadores de cânulas no rúmen e duodeno (tipo $T$ simples). Os animais foram mantidos em baias individuais cobertas com as laterais fechadas com madeira e piso de concreto, providas de comedouro e bebedouro.

As rações foram balanceadas de forma a apresentarem 11,0\% PB e 70,0\% de NDT (\% na MS), em uma relação de 50:50\% volumoso:concentrado. O farelo de soja e milho foram os alimentos que compuseram o concentrado e a silagem de milho, o volumoso. As três rações experimentais (Tabela 1) foram caracterizadas pela ausência ou presença de aditivos (ração testemunha, ração com ionóforo e ração com probiótico). A composição percentual da ração (\% da MS) foi a seguinte: $50 \%$ de silagem de milho, $40 \%$ de milho moído, $9 \%$ de farelo de soja e $1 \%$ de sal mineral (ração testemunha).

Os aditivos empregados nas rações foram o ionóforo 10\% monensina sódica - rumensin ${ }^{\circledR}$ e o probiótico - levedura (Saccharomyces cerevisiae $5 \times 10^{6} \mathrm{UFC} / \mathrm{g}+50 \mathrm{mg}$ Selênio + 300 mg Cromo) - beef - sacc ${ }^{\circledR}$.

O oferecimento da ração foi restrito a $2 \%$ PV para reduzir os efeitos do consumo sobre os coeficientes de digestão e fornecida aos animais em duas porções iguais, pela manhã (8h) e à tarde (16h), sendo o volumoso e o concentrado misturados no cocho. Também os aditivos foram adicionados no momento do fornecimento da ração na dosagem recomendada pelos fabricantes: $2 \mathrm{~g} / \mathrm{animal} / \mathrm{dia}$ - ionóforo (ração ionóforo) e 5 g/animal/dia - probiótico (ração probiótico). A dosagem foi dividida em duas doses, metade pela manhã (1 g - ionóforo e 2,5 g - probiótico) e metade no 
Tabela 1 - Composição nutricional dos alimentos e da ração experimental

\begin{tabular}{lcccccccc}
\hline Alimento & \%MS & MO & PB & FDN & FDA & EE & AM \\
& & \multicolumn{5}{c}{ CIA } \\
\hline Farelo de soja & 89,17 & 94,42 & 45,36 & 14,47 & 7,57 & 2,33 & 15,19 & 0,10 \\
Milho moído & 87,56 & 98,96 & 8,84 & 15,32 & 3,72 & 3,42 & 73,74 & 0,02 \\
Silagem de milho & 95,37 & 90,76 & 7,19 & 53,31 & 31,33 & 2,16 & 21,01 & 1,32 \\
Ionóforo $^{1}$ & 90,33 & 84,24 & 11,88 & 17,35 & 11,03 & 3,79 & 34,50 & - \\
Probiótico $^{2}$ & 92,39 & 85,72 & 38,57 & 2,79 & 1,2 & 3,43 & 3,91 \\
Ração & 59,95 & 93,61 & 11,21 & 34,09 & 17,84 & 2,66 & 41,37 & 0,78 \\
\hline
\end{tabular}

$\mathrm{AM}=$ amido; $\mathrm{CIA}=$ cinza insolúvel em ácido; ${ }^{1}$ monensina sódica - Rumensin ${ }^{\circledR} ;{ }^{2}$ levedura (Saccharomyces cerevisiae $5 \times 10^{6}$ UFC/g + selênio + cromo) Beef - $\operatorname{sacc}^{\circledR}$.

período da tarde. Os aditivos foram fornecidos em pequena fração da ração e, imediatamente após a ingestão pelos animais, foi colocado no cocho o restante da ração previamente pesada, repetindo-se o mesmo procedimento no período da tarde.

Para evitar acidentes durante a pesagem dos animais, como a retirada forçada da cânula duodenal, procedeu-se à estimativa do peso dos animais por meio de fita (perímetro torácico), ao final de cada período de adaptação e de cada período de coleta.

Cada período experimental teve duração de 21 dias, sendo 14 dias de adaptação e sete dias de coleta. Durante o período de coleta, foram amostrados cerca de $200 \mathrm{~mL}$ de digesta duodenal através da cânula e $100 \mathrm{~g}$ de fezes diretamente do reto, com intervalo de 12 horas e aumento de 2 horas entre dias consecutivos, totalizando 12 amostras por animal. As amostras foram armazenadas em sacos plásticos, devidamente identificadas e congeladas a $-20^{\circ} \mathrm{C}$.

Após o período de coleta, as amostras de alimento, fezes e digestas duodenais foram secas em estufa a $55^{\circ} \mathrm{C}$ por 96 horas, moídas ( $1 \mathrm{~mm}$ ) individualmente e misturadas em quantidades iguais, com base no peso seco, formando amostras compostas de fezes e digesta por animal e para cada ração.

Para determinação dos fluxos diários de matéria seca (MS) no duodeno e nas fezes, foi utilizado como indicador interno a cinza insolúvel em ácido (CIA), de acordo com a metodologia descrita por Van Keulen \& Young (1977).

As determinações de MS, matéria orgânica (MO), proteína bruta (PB) e extrato etéreo (EE) nas amostras de alimentos, sobras, fezes e digesta duodenal foram feitas segundo métodos descritos em Silva \& Queiroz (2002). As análises de fibra em detergente neutro (FDN) e fibra em detergente ácido (FDA) foram conduzidas segundo recomendações de Van Soest et al. (1991). O teor de amido (AM) das amostras foi analisado pelo método de Poore et al. (1989), adaptado por Pereira \& Rossi (1995).
Os coeficientes de digestibilidade aparente total e parcial da MS e dos nutrientes foram estimados de acordo com as fórmulas descritas em Coelho da Silva \& Leão (1979).

Utilizou-se delineamento experimental em dois quadrados latinos $3 \times 3$, com arranjo fatorial $3 \times 2$, correspondendo a três rações (testemunha, ionóforo e probiótico) e duas espécies (bubalina e bovina), sendo uma espécie em cada quadrado latino, para comparar consumo e os locais de digestão dos nutrientes. As análises estatísticas das variáveis estudadas foram interpretadas pelo Sistema de Análises Estatísticas e Genéticas - SAEG (UFV, 1998). Quando a interação espécie $\times$ tratamento foi significativa, procedeu-se à análise dos efeitos dos tratamentos dentro de cada espécie.

\section{Resultados e Discussão}

Não houve interação ração $\times$ espécie animal $(P>0,05)$, como também não houve diferença para as rações e por espécie $(\mathrm{P}>0,05)$ sobre os consumos médios de MS, MO e dos nutrientes PB, FDN, FDA, EE e AM (kg/dia e \% PV), uma vez que o consumo de MS foi restrito e as rações experimentais apresentaram teores semelhantes desses nutrientes na MS (Tabela 2). De modo geral, reduções nos consumos de MS, em bovinos, com a presença de ionóforo nas rações são relatadas na literatura (Goodrich et al., 1984; Nicodemo, 2001). De acordo com Bergen \& Bates (1984), em dietas com alto teor de grãos, ionóforos geralmente reduzem a ingestão de alimentos cerca de 8 a 10\% e melhoram a conversão alimentar, mantendo ou aumentando o ganho de peso diário, sem afetar as características de carcaça. Neste trabalho, verificou-se redução de 6,7\% no consumo de MS dos animais (\% PV) alimentados com ração contendo ionóforo em relação à testemunha.

Os consumos voluntários médios de MS para bubalinos e bovinos foram próximos (1,9\% do PV) ao pré-estabelecido para este estudo (2,0\% PV). Entretanto, menor consumo dos búfalos em relação aos bovinos foi relatado por Maeda et 
Tabela 2 - Consumo médio diário, em função das rações experimentais e da espécie animal

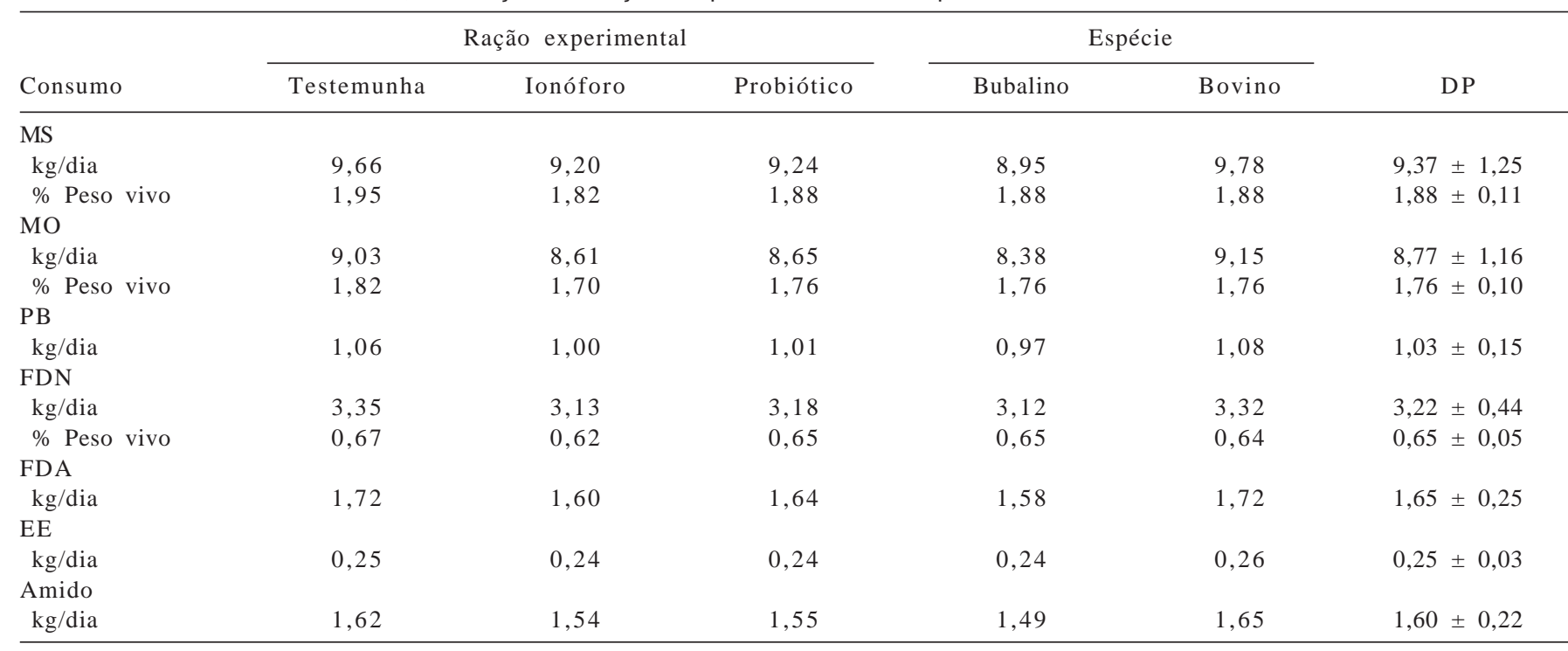

Médias seguidas com letras diferentes diferem $(P<0,05)$ entre si pelo teste Tukey; $D P=$ desvio-padrão.

al. (2007), ao avaliarem o consumo de MS e dos nutrientes em rações com três teores de concentrado (23, 43 e 63\%), com milho moído e resíduo desidratado de fécula de mandioca, farelo de soja e silagem de milho. Da mesma forma, Gomes (1982) e Gonçalves et al. (1991), ao compararem o consumo voluntário de grupos genéticos, observaram que, em média, búfalos e zebuínos consomem menos MS que novilhos holandeses. Segundo Bartocci et al. (1997), os bubalinos apresentam maior tempo de retenção da digesta no rúmen-retículo em relação aos bovinos, o que pode explicar, parcialmente, os menores consumos.

Não houve interação ração (ausência ou presença de aditivos) $\times$ espécie para os coeficientes de digestibilidade aparente total (CDT) da MS e demais nutrientes, porém diferenças $(\mathrm{P}<0,05)$ foram observadas para os $\mathrm{CDT}$ de $\mathrm{MS}$, MO, PB, FDN, FDA, EE e AM, em função das rações experimentais, e para os CDT da PB, FDN e AM, por espécie animal (Tabela 3).

A adição de ionóforo em ração com $50 \%$ de volumoso e $50 \%$ de concentrado aumentou $(\mathrm{P}<0,05)$ os CDT da MS, da $\mathrm{MO}$, da $\mathrm{PB}$ e do EE em relação às demais rações, com exceção do CDT do amido, que não diferiu entre as rações com aditivos, porém foi superior à testemunha. Possivelmente, os resultados observados decorreram da alteração na microbiota ruminal, tendo efeito sobre os processos que afetam diretamente o metabolismo energético e protéico, pois, de acordo com Spears (1990), os ionóforos selecionam uma comunidade bacteriana que produz mais propionato e menos lactato, acetato e butirato e, indiretamente, menos metano. O valor do CDT da MS obtido com a presença de ionóforo está próximo aos observados em ovinos deslanados da raça Santa Inês submetidos a rações com relação volumoso:concentrado 50:50\% e adição de monensina sódica na dosagem de 0 e $40 \mathrm{mg} / \mathrm{animal} / \mathrm{dia}$ (71,8 vs 70,7\%), não diferindo entre si (Rodrigues et al., 2001).

Os dados deste trabalho corroboram os encontrados por outros pesquisadores que observaram aumento da digestibilidade aparente da PB com o uso de ionóforos na dieta (Russell, 1996; Lana et al., 2000; Barbosa et al., 2001).

Com relação ao uso de probiótico na ração, com exceção do CDT da PB, que foi inferior ( $\mathrm{P}<0,05)$, os CDT da FDN, da FDA e do amido foram superiores $(\mathrm{P}<0,05)$ e os CDT da MS e MO, semelhantes $(\mathrm{P}>0,05)$ aos da ração testemunha.

Os aumentos verificados na digestibilidade da FDN e FDA, com o uso do probiótico nas rações, parecem estar relacionados à melhor atividade das bactérias celulolíticas. Segundo Nicodemo (2001), os diferentes gêneros de Saccharomyces têm grande afinidade por oxigênio, melhorando as condições do rúmen para os microrganismos anaeróbicos. Segundo Queiroz et al. (2004), a remoção de $\mathrm{O}_{2}$ do rúmen por Saccharomyces cerevisiae proporciona aumento no número de bactérias celulolíticas viáveis, pois o oxigênio é tóxico a essas bactérias anaeróbicas, reduzindo a adesão destas à celulose. Ainda, além dos efeitos relacionados ao melhor desempenho de alguns tipos de bactérias, outros foram citados como o fornecimento de fatores de crescimento - vitaminas (complexo B, ácido para-amino benzóico etc), ácidos dicarboxílicos (fumarato, malato etc), efeito tampão e redução do número de protozoários (Callaway \& Martin, 1997).

Resultados semelhantes para os CDT da MS sem (79,2\%) e com (77,8\%) a adição de levedura (Saccharomyces 
Tabela 3 - Coeficientes de digestibilidade aparente total e parcial dos nutrientes, em função das rações experimentais e da espécie animal

\begin{tabular}{|c|c|c|c|c|c|c|}
\hline \multirow[b]{2}{*}{ Item } & \multicolumn{3}{|c|}{ Ração experimental (\% MS) } & \multicolumn{2}{|c|}{ Espécie } & \multirow[b]{2}{*}{$\mathrm{DP}^{3}$} \\
\hline & Testemunha & Ionóforo & Probiótico & Bubalino & Bovino & \\
\hline \multicolumn{7}{|c|}{ Coeficiente de digestibilidade aparente total } \\
\hline MS & $62,1 \mathrm{~B}$ & $68,0 \mathrm{~A}$ & $63,3 \mathrm{~B}$ & 64,0 & 64,9 & $64,5 \pm 2,8$ \\
\hline MO & $63,8 \mathrm{~B}$ & 70,4A & $64,9 B$ & 66,8 & 65,9 & $66,4 \pm 3,1$ \\
\hline PB & $61,8 \mathrm{~B}$ & $66,2 \mathrm{~A}$ & $59,1 \mathrm{C}$ & $61,5 b$ & $63,3 a$ & $62,8 \pm 3,5$ \\
\hline FDN & $52,7 \mathrm{~B}$ & $52,3 \mathrm{~B}$ & $55,7 \mathrm{~A}$ & $54,9 \mathrm{a}$ & $52,2 b$ & $53,6 \pm 2,3$ \\
\hline FDA & $42,4 \mathrm{~B}$ & $43,9 \mathrm{AB}$ & $45,5 \mathrm{~A}$ & 44,5 & 43,5 & $43,9 \pm 1,6$ \\
\hline $\mathrm{EE}$ & $72,3 \mathrm{~B}$ & $77,6 \mathrm{~A}$ & $73,6 \mathrm{~B}$ & 75,0 & 74,0 & $74,5 \pm 2,9$ \\
\hline $\mathrm{AM}$ & $85,6 \mathrm{~B}$ & $88,2 \mathrm{~A}$ & $88,2 \mathrm{~A}$ & $86,0 \mathrm{~b}$ & $88,4 a$ & $87,3 \pm 2,0$ \\
\hline \multicolumn{7}{|c|}{ Coeficiente de digestibilidade ruminal } \\
\hline $\mathrm{MO}^{1}$ & $59,5 \mathrm{AB}$ & $59,1 \mathrm{~B}$ & $61,5 \mathrm{~A}$ & $61,2 \mathrm{a}$ & $59,0 \mathrm{~b}$ & $60,1 \pm 1,9$ \\
\hline $\mathrm{FDN}^{1}$ & $90,2 \mathrm{~B}$ & $94,4 \mathrm{~A}$ & $91,8 \mathrm{AB}$ & $94,0 \mathrm{a}$ & $90,3 b$ & $92,2 \pm 2,9$ \\
\hline FDA $^{1}$ & $64,0 \mathrm{~B}$ & $70,0 \mathrm{~A}$ & $72,9 \mathrm{~A}$ & $70,3 a$ & $67,6 b$ & $68,9 \pm 4,9$ \\
\hline $\mathrm{AM}^{1}$ & $80,6 \mathrm{AB}$ & $81,2 \mathrm{~A}$ & $79,8 \mathrm{~B}$ & $81,1 \mathrm{a}$ & $80,0 \mathrm{~b}$ & $80,5 \pm 1,1$ \\
\hline $\mathrm{AM}^{2}$ & $68,9 \mathrm{C}$ & $71,4 \mathrm{~A}$ & $70,4 \mathrm{~B}$ & $69,6 b$ & $70,9 a$ & $70,3 \pm 1,5$ \\
\hline \multicolumn{7}{|c|}{ Coeficiente de digestibilidade intestinal } \\
\hline $\mathrm{MO}^{1}$ & $40,5 \mathrm{AB}$ & $40,9 \mathrm{~A}$ & $38,5 B$ & $38,8 b$ & $41,0 \mathrm{a}$ & $39,9 \pm 1,9$ \\
\hline $\mathrm{PB}^{2}$ & $58,6 \mathrm{~B}$ & $64,5 \mathrm{~A}$ & $55,6 \mathrm{C}$ & $58,4 b$ & $60,7 a$ & $59,5 \pm 3,3$ \\
\hline $\mathrm{FDN}^{1}$ & $9,8 \mathrm{~A}$ & $5,6 \mathrm{~B}$ & $7,8 \mathrm{AB}$ & $6,0 \mathrm{~b}$ & $9,6 \mathrm{a}$ & $7,7 \pm 2,9$ \\
\hline $\mathrm{FDA}^{1}$ & $36,0 \mathrm{~A}$ & $30,1 \mathrm{~B}$ & $27,1 \mathrm{~B}$ & 29,7 a & $32,4 a$ & $31,0 \pm 4,9$ \\
\hline $\mathrm{AM}^{2}$ & $53,5 \mathrm{~B}$ & $58,6 \mathrm{~A}$ & $60,3 \mathrm{~A}$ & $53,9 b$ & $61,1 \mathrm{a}$ & $57,5 \pm 3,6$ \\
\hline
\end{tabular}

Médias com letras maiúsculas comparam médias nas linhas entre rações experimentais (testemunha, ionóforos e probiótico) e letras minúsculas, médias nas linhas entre as espécies (bubalino e bovino). Médias seguidas de letras diferentes diferem $(P<0,05)$ entre si pelo teste Tukey.

$1 \%$ do total digerido; ${ }^{2} \%$ da quantidade que chegou a cada local; ${ }^{3}$ Probabilidades: DP = desvio-padrão; AM = amido.

cerevisiae $8 \times 10^{9} \mathrm{UFC} / \mathrm{g}$ do produto - Beef-Sac) também foram observados por Greene (2002) para dietas contendo $90 \%$ de concentrado, fornecidas a novilhos com consumo de $9,8 \mathrm{~kg} \mathrm{MS} /$ dia.

Os maiores valores $(\mathrm{P}<0,05)$ de $\mathrm{CDT}$ do amido foram obtidos para as rações com ionóforo e probiótico de $88,2 \%$, que não diferiram entre si $(\mathrm{P}>0,05)$, em relação à ração testemunha (85,6\%). Van Nevel (1991) concluiu que os ionóforos não provocam alteração na digestibilidade do amido. Todavia, o uso de ionóforos tem sido sugerido como forma de diminuir os efeitos da ingestão elevada de amido sobre o ambiente ruminal. Entretanto, a produção de propionato não é a principal responsável pela redução do $\mathrm{pH}$, mas sim o acúmulo de ácido láctico (ácido forte - pKa mais baixo), um intermediário na produção de propionato pela via do acrilato (Owens et al., 1998).

Com relação às espécies, houve efeito para os CDT da $\mathrm{PB}, \mathrm{FDN}$ e amido, sendo que os bovinos apresentaram maiores $\mathrm{CDT}$ da $\mathrm{PB}$ e do amido $(\mathrm{P}<0,05)$ e os búfalos, maiores CDT da FDN $(\mathrm{P}<0,05)$. Para o CDT da PB, diferentemente do observado nesta pesquisa, Rodrigues et al. (2001) não encontraram diferença na digestibilidade total da PB entre búfalos (46,2\%) e bovinos (43,3\%) alimentados com rações contendo relação volumoso:concentrado de 40:60. Da mesma forma, Maeda et al. (2007) não observaram diferença entre bovinos e bubalinos para o CDT da PB, com valor médio de $58,7 \%$ para rações com diferentes teores de concentrado (23, 43 e 63\%). Embora neste trabalho tenha sido constatada diferença $(\mathrm{P}<0,05)$ entre bovinos e bubalinos, essa foi biologicamente pequena (63,3 vs $61,5 \%)$.

O maior valor para o CDT da FDN encontrado para os bubalinos em relação aos bovinos corrobora alguns resultados de autores que observaram maior digestibilidade da fração fibrosa pelos bubalinos em comparação aos bovinos (Devendra, 1983; Hussain \& Cheeke, 1996), porém Souza et al. (2000) e Maeda et al. (2007) não encontraram diferença entre bovinos $(54,0 \%)$ e bubalinos (55,9\%) sob dietas com níveis crescentes de FDN. Segundo Kawashima (2005), as diferenças observadas para a digestão da fibra entre bubalinos e bovinos estariam relacionadas às dietas de baixa qualidade, fato que não ocorreu neste trabalho, pois houve melhor aproveitamento da fibra pelos búfalos em ração com 50:50\% de volumoso:concentrado.

Os bovinos apresentaram maior CDT do amido $(\mathrm{P}<0,05)$ que os bubalinos. Também, Maeda et al. (2007) encontraram valores superiores para o CDT do AM em bovinos em relação aos bubalinos (95,7 vs 85,8\%).

Para os coeficientes de digestibilidade ruminal (CDR) da MO, da FDN, da FDA e do amido, não houve interação 
rações $\times$ espécie, porém diferiram $(\mathrm{P}<0,05)$ para rações (sem ou com aditivos) e espécies.

Como resultado da fermentação ruminal, em função da adição de ionóforo e de probiótico nas rações, verificaram-se os maiores CDR da FDA $(\mathrm{P}<0,05)$ como \% do total digerido, em relação à ração testemunha. Entretanto, para o CDR da FDN, apenas a adição ionóforo diferiu $(\mathrm{P}<0,05)$ da ração testemunha, pois a adição do probiótico foi semelhante às rações com ionóforo e testemunha.

Possíveis discussões do efeito do ionóforo sobre a digestibilidade da fibra têm sido comumente atribuídas, na literatura, ao aumento do tempo de retenção da MS no rúmen (Ellis et al. 1983), ao menor consumo voluntário de alimentos (Roger \& Davis, 1982), à melhora das condições ruminais (Branine \& Galyean, 1990) ou ao aumento no estímulo à ruminação (Knowlton et al., 1996). Segundo Van Nevel \& Demeyer (1988), o efeito da monensina na degradação da fibra ainda não está esclarecido. Segundo Domescik \& Martin (1999), a utilização dos ionóforos poderia diminuir a digestibilidade da FDN, em razão da redução da atividade dos microrganismos celulolíticos. No entanto, observou-se efeito benéfico da monensina sobre a digestibilidade ruminal da FDN e FDA em rações com $50 \%$ de silagem de milho e $50 \%$ de concentrado e consumos de MS e FDN, respectivamente, de 1,8 e $0,62 \%$ do $P V$.

Por outro lado, o efeito benéfico da presença do probiótico na digestibilidade ruminal da FDA pode ser atribuído à ação da presença das leveduras, que, entre outras, aumenta o número de bactérias, especialmente as celulolíticas, reduz os teores de amônia e aminas tóxicas, diminui os teores de lactato e garante maior estabilidade do pH ruminal (Harris, 1994, citado por Simas, 2000).

A digestibilidade ruminal do amido (porcentagem do que chega ao local) foi influenciada $(\mathrm{P}<0,05)$ pela inclusão de ionóforo, que apresentou valor de $71,4 \%$, seguido da ração com probiótico $(70,4 \%)$ e da ração testemunha (68,9\%). Todavia, para o CDR do AM, quando expresso em relação ao total digerido, a adição do ionóforo aumentou a digestão ruminal do amido em relação ao probiótico, porém não diferiu da ração testemunha. Trabalhos revisados por Van Nevel (1991) mostraram que a digestibilidade ruminal do amido não foi alterada pela inclusão de monensina sódica à dieta. Todavia, o autor ressaltou que, para o processo de otimização da fermentação ruminal, a minimização da fermentação ruminal do amido seria o melhor resultado.

Verificou-se maior digestão ruminal da $\mathrm{MO}$ (porcentagem do total digerido) $(\mathrm{P}<0,05)$ para os búfalos $(61,2 \%)$ que para os bovinos (59,0\%). Em média, para ambas as espécies, 60,1\% de MO foi digerido no rúmen, valor inferior ao preconizado pelo AFRC (1993), de 65,0\%, para MO aparentemente digerida no rúmen para várias dietas.

Os búfalos apresentaram os maiores CDR da FDN, da FDA e do amido (porcentagem do total digerido) que os bovinos. Os maiores CDR da FDN e FDA observados para os búfalos foram relacionados ao maior $\mathrm{pH}$ ruminal, em razão de secreção salivar mais intensa (Sivkova et al., 1997), maior atividade celulolítica, melhor aproveitamento dos componentes fibrosos no rúmen dos bubalinos (Tewatia \& Bhatia, 1998) e maior número de protozoários ciliados pertencentes à subfamília Diplodiniinae (Franzolin \& Franzolin, 2000). Os maiores volumes ruminal e o maior tempo de permanência da digesta no rúmen (Bartocci et al., 1997) também podem refletir em maior fermentação dos carboidratos estruturais, pois, segundo Terramoccia et al. (2000), os búfalos apresentaram menor taxa de passagem de sólidos $\left(0,0246 \mathrm{~h}^{-1}\right)$ que os bovinos $\left(0,0298 \mathrm{~h}^{-1}\right)$.

Para o CDR do amido, expresso em relação à quantidade que chega ao local, observou-se menor fermentação do amido $(\mathrm{P}<0,05)$ no trato digestório dos búfalos em relação aos bovinos (70,9 vs 69,6\%). Entretanto, apesar dessas diferenças parecem ser biologicamente insignificantes, Maeda et al. (2007) também observaram que a digestibilidade ruminal do amido foi influenciada pela espécie, obtendo-se médias (\% do que chega ao local) de 83,7 e $70,2 \%$ para bovinos e búfalos, respectivamente.

A presença de ionóforo aumentou a digestibilidade intestinal (\% do que chega ao local) da PB e do amido $(\mathrm{P}<0,05)$ em relação à ração testemunha. Entretanto, o coeficiente de digestibilidade intestinal (CDI) do amido não diferiu com a adição do ionóforo ou probiótico, mas o CDI da PB foi prejudicado pela presença do probiótico.

Para os carboidratos estruturais, os CDI da FDN e FDA (porcentagem do total digerido), em presença de probiótico e ionóforo, foram reduzidos neste compartimento em relação à ração testemunha, uma vez que esses aditivos tiveram efeito positivo na digestão ruminal, aumentando a degradabilidade dos carboidratos fibrosos.

Verificou-se que a digestão intestinal da PB e do amido (porcentagem do que chega ao local) foi superior nos bovinos, provavelmente em decorrência do menor tempo de permanência da digesta nos intestinos, devido ao menor comprimento destes em búfalos em relação aos bovinos (Bartocci et al., 1997). Segundo Angulo et al. (2005), os bubalinos apresentam intestino delgado menor que os taurinos (26,5 vs 39,5 m).

O menor valor de CDI do AM observado para os búfalos (53,9 vs $61,1 \%)$ também pode estar relacionado ao incremento do fluxo de amido para o intestino e ao 
curto período de adaptação. Segundo Croom et al. (1992), citados por Zeoula \& Caldas Neto (2001), a limitação intestinal em relação ao amido pode decorrer da falta de sincronização entre o fluxo de amido para o intestino e a secreção de amilase. Maeda et al. (2007) também observaram para digestão intestinal do AM (\% do que chega ao local) valor superior para bovinos (70,9\%) em relação aos bubalinos (52,3\%). É provável que os búfalos, por serem animais rústicos e não terem sofrido seleção tão intensa como os bovinos quanto à alimentação rica em concentrados, apresentem limitações mais acentuadas quanto à digestibilidade intestinal do amido.

Houve interação $(\mathrm{P}<0,05)$ de rações (sem ou com aditivo) $\chi$ espécie sobre os CDR e CDI da MS, PB e do EE (Tabela 4).

Para ambas as espécies, a adição de ionóforo foi efetiva $(P<0,05)$ em aumentar a fermentação ruminal da MS, reduzir a degradação da PB no rúmen e elevar o CDI da PB, quando expresso como \% do total digerido. Um dos benefícios da monensina é a redução na fermentação de proteína ruminal, e, conseqüentemente, o incremento da disponibilidade de proteína no intestino delgado do animal. Isto ocorre em decorrência das reduções na produção de amônia ruminal como conseqüência da menor fermentação da proteína, como já demonstrado em experimentos in vitro e in vivo conduzidos por Dinius et al. (1976) e Van Nevel \& Demeyer (1977). Russell \& Martin (1984) relataram que o uso de ionóforos na ração diminui o crescimento de bactérias proteolíticas e inibe a deaminação e proteólise, sendo a deaminação mais afetada que a proteólise. Segundo Barbosa et al. (2001), a administração de inibidores bacterianos, como a monensina, seria uma forma de reduzir as perdas de nitrogênio pelo animal.
Assim, o CDR da PB (\% do chega ao local) da ração com a adição de ionóforo destacou-se por apresentar em ambas as espécies os menores valores. Estes resultados são condizentes com a literatura, visto que os ionóforos parecem reduzir a degradação da proteína ruminal, sem diminuir ou afetando pouco a proteólise, porém reduzindo a degradação de peptídeos (Lana et al., 2000; Oliveira et al., 2004).

Para os bovinos, a adição do probiótico diferiu da ração testemunha $(\mathrm{P}<0,05)$, aumentado o CDR da MS. Porém, para a espécie bubalina, não houve diferença $(\mathrm{P}>0,05)$ entre a adição ou não do probiótico para essa mesma variável. De acordo com alguns autores (Newbold et al., 1995; Nicodemo, 2001), o uso de fungos unicelulares, especialmente do gênero Saccharomyces, na alimentação de bovinos de corte, estaria relacionado ao aumento na digestibilidade ruminal da MS, especialmente da fibra.

Beleze (2005), em estudos de digestibilidade in vitro da MS, observou interação da adição de ionóforo e probiótico $\times$ espécie animal. Os resultados in vitro confirmaram os resultados obtidos em estudos in vivo com relação ao uso do probiótico para a espécie bubalina sobre a fermentação ruminal da MS. A inclusão de probiótico em rações para búfalos pareceu desnecessária, provavelmente em razão do maior número de microrganismos celulolíticos nessa espécie. Contudo, para a espécie bovina, a presença de probiótico teve efeito positivo em dietas com $50 \%$ de concentrado.

Os búfalos, em relação aos bovinos, apresentaram maior CDR da MS, independentemente da adição de aditivos às rações. Garcia (1982) não observou diferença na digestão ruminal da MS entre Holandês, Zebu, 1/2 Holandês-Zebu e búfalo; porém verificou tendência de maior digestão ruminal da MS para o búfalo, quando alimentado com ração que

Tabela 4 - Coeficientes de digestibilidade ruminal e intestinal, em função da interação rações experimentais $\times$ espécie animal

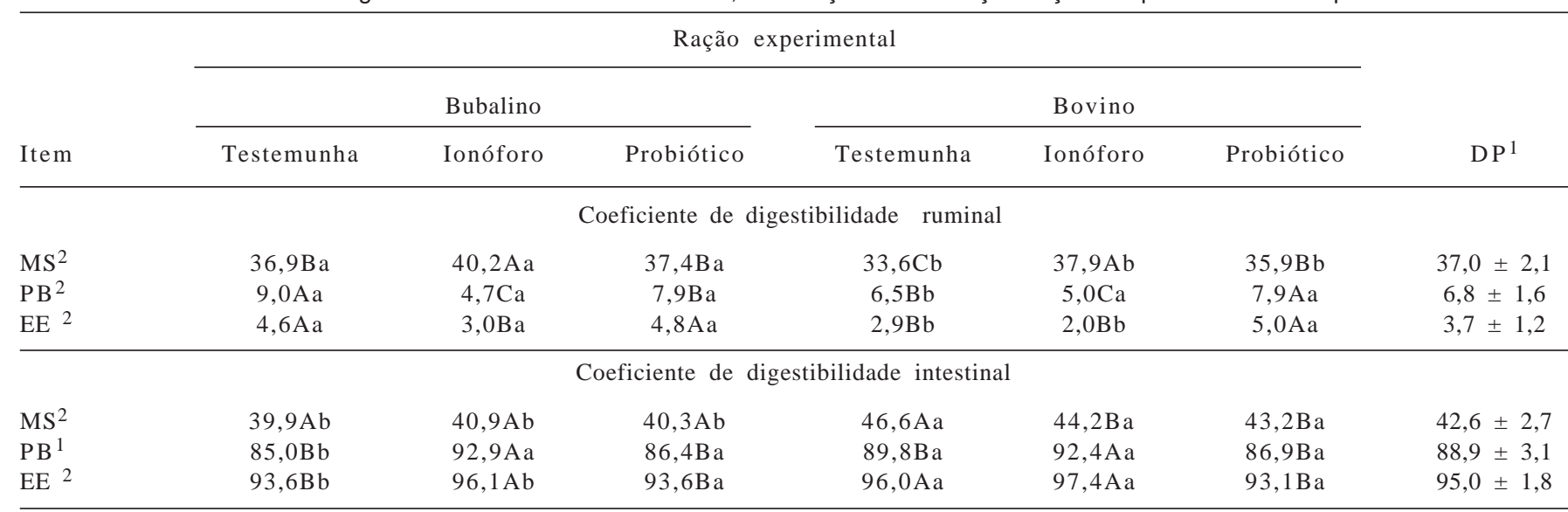

Letras maiúsculas comparam médias nas linhas entre rações experimentais (testemunha, ionóforo e probiótico) dentro da espécie (bubalino e bovino) e letras minúsculas, médias nas linhas entre as espécies dentro das rações experimentais. Médias seguidas com letras diferentes diferem $(P<0,05)$ entre si pelo teste Tukey.

$1 \%$ do total digerido; ${ }^{2} \%$ da quantidade que chegou a cada local; DP = desvio-padrão. 
continha $40 \%$ de volumoso e $60 \%$ de concentrado em comparação à ração com $40 \%$ de concentrado.

Quando se observa o CDR da PB (\% do que chega ao local) para a ração testemunha, os resultados indicaram maior digestão da proteína no rúmen para os búfalos e conseqüente desaparecimento do nitrogênio, o que significou maior absorção de amônia pela parede do rúmen. De fato, as concentrações de amônia ruminal para os búfalos após quatro horas do fornecimento da ração permaneceram numericamente elevadas quando comparadas às dos bovinos (Beleze, 2005) embora sem diferença $(P>0,05)$ entre as espécies.

Os valores de CDR do EE (\% do que chega ao local) normalmente foram baixos e a adição do ionóforo os reduziu ainda mais, independentemente da espécie. Por outro lado, a digestibilidade intestinal do EE, para ambas as espécies, foi aumentada com a adição de ionóforo em relação ao probiótico na ração, mas para espécie bovina o ionóforo não diferiu da ração testemunha. Independentemente da adição ou não do ionóforo, os bovinos apresentaram maiores CDI do EE que os búfalos.

Quanto à digestão intestinal da MS, com adição ou não dos aditivos, os bovinos apresentaram valores superiores aos bubalinos, observando-se o mesmo comportamento para o CDI da PB e EE para ração testemunha. As adições do ionóforo e probiótico reduziram esses efeitos sobre os CDI da PB e EE entre bovinos e bubalinos. Da mesma forma, Maeda et al. (2007) verificaram maiores CDI da MS (\% do que chega ao local) para bovinos (44,8\%) em relação aos búfalos $(39,1 \%)$, porém, para o CDI da PB, não houve diferenças entre as espécies. Estes dados novamente corroboram as observações de Bartocci et al. (1997) e Angulo et al. (2005) sobre o menor aproveitamento nos intestinos em búfalos, provavelmente devido ao menor comprimento.

\section{Conclusões}

A adição da monensina sódica em rações com 50:50\% de volumoso:concentrado tem efeito benéfico sobre a fermentação ruminal e a utilização dos nutrientes em bovinos e bubalinos.

A adição de probiótico (Saccharomyces cerevisiae + selênio + cromo) tem efeito positivo sobre a fermentação ruminal e a utilização da fração da fibra, principalmente àquela ligada à lignina, e propicia maior absorção intestinal do amido em bovinos e bubalinos.

Os bovinos aproveitam melhor a proteína e o amido que os búfalos e estes, mais a fração fibrosa de ração com relação volumoso:concentrado de 50:50\%.

\section{Literatura Citada}

AGRICULTURAL AND FOOD RESEARCH COUNCIL - AFRC. Energy and protein requeriment of ruminants. Wallingford: CAB International, 1993. 159p.

ANGULO R.A.; NOGUERA, R.R. BERDUGO, J.A. [2005]. El búfalo de agua (Bubalus bubalis) un eficiente utilizador de nutrientes: aspectos sobre fermentación y digestión ruminal. Livestock Research for Rural Development, v.17, n.6, 2005. Disponível em: http://www.cipav.org.co/ Acesso em: 10/1/2005.

BARBOSA, N.G.S.; LANA, R.P.; MÂNCIO, A.B. Fermentação da proteína de seis alimentos por microrganismos ruminais, incubados puros ou com monensina ou rumensin ${ }^{\circledR}$. Revista Brasileira de Zootecnia, v.30, n.4, p.1316-1324, 2001.

BELEZE, J.F.R. Digestibilidade e parâmetros ruminais de rações com teores de concentrado e adição de ionóforo ou probiótico para bovinos e bubalinos. Maringá: Universidade Estadual de Maringá, 2005. 161p. Tese (Doutorado em Zootecnia) - Universidade Estadual de Maringá, 2005.

BERGEN, W.G.; BATES, D.B. Ionophores: their effect on production efficiency and mode of action. Journal of Animal Science, v.58, n.6, p.1465-1483, 1984

BRANINE, M.E.; GALYEAN, M.L. Influence of grain and monensin supplementation on ruminal fermentation, intake, digesta kinetics and incidence and severity of frothy bloat in steers grazing winter wheat pasture. Journal of Animal Science, v.68, n.5, p.1139-1150, 1990.

BARTOCCI, S.; AMICI, A.; VERNA, M. et al. Solid and fluid passage rate in buffalo, cattle, and sheep fed diets with different forage to concentrate ratios. Livestock Production Science, v.52, n p.201-208, 1997.

CALLAWAY, E.S.; MARTIN, S.A. Effects of a Saccharomyces cerevisiae culture on animal bacteria that utilize lactate and digest cellulose. Journal of Dairy Science, v.80, n.9, p.20352044, 1997.

COELHO DA SILVA, J.F.; LEÃO, M.I. Fundamentos de nutrição de ruminantes. Piracicaba: Livroceres, 1979. 380p

DEVENDRA, C. The utilization of nutrient, feeding systems and nutrient requirements of swamp buffaloes. In: SIMPOSIUM ON THE WATER BUfFaloes, 1983, Tsukuba. Proceedings... Tsukuba: 1983. 34p.

DINIUS, D.A.; SIMPSON, M.E.; MARSH, P.B. Effect of monensina fed with forage on digestion and the ruminal ecosystem of steers. Journal of Animal Science, v.42, n.1, p.229-234, 1976.

DOMESCIK, E.J.; MARTIN, S.A. Effects of laidiomycin propionate and monensina on the in vitro mixed ruminal microorganism fermentation. Journal of Animal Science, v.56, n.8, p.2305-2312, 1999.

ELLIS, W.C.; HORN, G.W.; DELANEY, D. et al. Effects of ionophores on grazed forage utilization and their economic value for cattle on wheat pasture. In: NATIONAL WHEAT PASTURE SYMPOSIUM, 1983, Stillwater. Proceedings... Stillwater: Agricultural Experimental Station, 1983. p.343.

FRANZOLIN, R.; FRANZOLIN, M.H.T. Efeitos de dietas com polpa cítrica em substituição ao milho em grão no concentrado sobre a degradabilidade e a fauna ruminal em bubalinos. Revista Brasileira de Zootecnia, v.29, n.6, p.2109-2118, 2000.

GARCIA, A.B. Digestão parcial e total de carboidratos em quatro diferentes grupos genéticos de novilhos. Viçosa, MG: Universidades Federal de Viçosa, 1982. 68p. Dissertação (Mestrado em Zootecnia) - Universidades Federal de Viçosa, 1982.

GOMES, S.Z. Digestão parcial e total da proteína e energia e consumo voluntário de matéria seca por diferentes grupos genéticos de bovinos. Viçosa, MG: Universidade Federal de Viçosa, 1982. 106p. Tese (Doutorado em Zootecnia) Universidade Federal de Viçosa, 1982.

GONÇALVES, L.C.; COELHO DA SILVA, J.F.C.; ESTEVÃO, M.M. et al. Consumo e digestibilidade da matéria seca e da energia em 
zebuínos e taurinos, seus mestiços e bubalinos. Revista Brasileira de Zootecnia, v.20, n.4, p.384-395, 1991.

GOODRICH, R.D.; GARRETT J.E.; GHAST, D.R. et al. Influence of monensin on the performance of cattle. Journal of Animal Science, v.58, n.6, p.1484-1498, 1984.

GREENE, W. Use of Saccharomyces cerevisiae in beef cattle. In: SIMPÓSIO GOIANO SOBRE MANEJO E NUTRIÇÃO DE BOVINOS DE CORTE, 4., 2002, Goiânia. Anais... Goiânia: Colégio Brasileiro de Nutrição Animal, 2002. p.79-96.

HUSSAIN, I.; CHEEKE, P.R. Evaluation of annual ryegrass straw corn juice silage with cattle and water buffalo: digestibility in cattle vs buffalo, and growth performance and subsequent lactational performance of Holstein heifers. Animal Feed Science and Technology, v.57, n.3, p.195-202, 1996.

KAMALAMMA, U.; KRISHNAMOORTY, U.; KRISHNAPPA, P. Effect of feeding yeast culture (Yea-sacc ${ }^{1026}$ ) on rumen fermentation in vitro and production performance in crossbred dairy cows. Animal Feed Science Technology, v.57, n.3, p.247-256, 1996.

KAWASHIMA, T. [2005]. Role of native ruminants in establishment of sustainable agricultural systems in northeast Thailand. Disponivel em: http://ss.jircas.affrc.go.jp/ kanko/working\%20report/No.30/30-01-10.pdf. Acesso em: $10 / 1 / 2005$.

KNOWLTON, K.F.; ALLEN, M.S.; ERIKSON, P.S. Lasalocid and particle size of corn for dairy cows in early lactation: 2. Effect on ruminal measurements and feeding behavior. Journal of Dairy Science, v.79, n.4, p.565-574, 1996.

LANA, R.P.; CUNHA, L.T.; BORGES, A.C. Efeito da monensina na fermentação da proteína de algumas fontes de alimentos. Revista Brasileira de Zootecnia, v.29, n.3, p.1868-1875, 2000.

MAEDA, E.M.; ZEOULA, L.M.; GERON, L.J.V. et al. Digestibilidade e características ruminais de dietas com diferentes teores de concentrado para bubalinos e bovinos. Revista Brasileira de Zootecnia, v.36, n.3, p.716-726, 2007.

NEWBOLD, C.J.; WALLACE, R.J.; CHEN, X.B. et al. Different strains of Saccharomyces cerevisiae differ in their effects on ruminal bacterial numbers in vitro and in sheep. Journal of Animal Science, v.73, n.6, p.1811-1818, 1995.

NICODEMO, M.L.F. Uso de aditivos na dieta de bovinos de corte. Campo Grande: Embrapa Gado de Corte, 2001. p.9-53.

OLIVEIRA, J.S.; LANA, R.P.; BORGES, A.C. et al. Efeito da monensina e extrato de própolis sobre a produção de amônia e degradabilidade in vitro da proteína bruta de diferentes fontes de nitrogênio. Revista Brasileira de Zootecnia, v.33, n.2, p.504-510, 2004.

OWENS, F.N.; SECRIST, D.S.; HILL, W.J. et al. Acidosis in cattle: a review. Journal of Animal Science, v.76, n 1, p.275, 1998.

PASSINI, R.; RODRIGUES, P.H.M.; CASTRO, A.L. et al. Parâmetros de fermentação ruminal em bovinos alimentados com grãos de milho ou sorgo de alta umidade ensilados. Revista Brasileira de Zootecnia, v.32, n.5, p.1266-1274, 2003.

PEREIRA, J.R.A.; ROSSI, P. Manual prático de avaliação nutricional de alimentos. Piracicaba: Fundação de Estudos Agrários Luiz de Queiroz, 1995. 34p.

QUEIROZ, R.C.; BERGAMASCHINE, A.F.; BASTOS, J.F.P. et al. Uso de produto à base de enzima e levedura na dieta de bovinos: Digestibilidade dos nutrientes e desempenho em confinamento. Revista Brasileira de Zootecnia, v.33, n.6, p.1548-1556, 2004.

RODRIGUES, P.H.M.; MATTOS, W.R.S.; MELOTTI, L. et al. Monensina e digestibilidade aparente em ovinos alimentados com proporções de volumoso/concentrado. Scientia Agrícola, v.58, n.3, p.449-455, 2001.
ROGERS, J.A.; DAVIS, C.L. Rumen volatile acid fatty production and nutrient utilization in steers fed a diet supplemented with sodium bicarbonate and monensin. Journal of Dairy Science, v.65, n.6, p.944-952, 1982.

RUSSELL, J.B. Bacteria: mechanisms of ionophore action in ruminal bacteria. In: SYMPOSIUM SCIENTIFIC UP DATE ON RUMENSIN/TYLAN FOR THE PROFESSIONAL FEEDLOT CONSULTANT, 1996, Amarillo, TX, Indianapolis, IN, Proceedings... Indianapolis: Elanco Animal Health, 1996. p.E1-E19.

RUSSELL, J.B.; MARTIN, S.A. Effects of various methane inhibitors on the fermentation of amino acids by mixed rumen microorganisms in vitro. Journal of Animal Science, v.59, n.5, p.1329-1338, 1984.

SILVA, D.J.; QUEIROZ. A.C. Análise de alimentos: métodos químicos e biológicos. 3.ed. Viçosa, MG: Editora UFV, 2002. 235p.

SIMAS, J.M.; NUSSIO, C.M. Uso de aditivos para vacas leiteiras. In: SIMPÓSIO INTERNACIONAL DE BOVINOCULTURA LEITEIRA, 1., 2000, Lavras. Anais... Lavras: Universidade Federal de Lavras, 2000. p.1-15.

SIVKOVA, K.; TRUFCHEV, H.; VARLIAKOV, I. Comparative studies on fermentation processes in the rumen and blood content of calves and buffalo calves I. Effect on diet, containing alfafa haylage. In: WORLD BUFFALO CONGRESS, 5., 1997, Caserta. Proceedings... Caserta: 1997. p.312-316.

SOUZA, N.H.; FRANZOLIN, R.; RODRIGUES, P.H.M. et al. Efeitos de níveis crescentes de fibra em detergente neutro na dieta sobre a digestão ruminal em bubalinos e bovinos. Revista Brasileira de Zootecnia, v.29, n.5, p.1565-1577, 2000.

SPEARS, J.W. Ionophores and nutrient digestion and absorption in ruminants. Journal of Nutrition, v.120, n.6, p.632-638, 1990.

TERRAMOCCIA, S.; BARTOCCI, S.; AMICI, A. et al. Protein and protein-free dry matter rumen degradability in buffalo, cattle, and sheep fed diets with different forage to concentrate ratios. Livestock Production Science, v.65, p.185-195, 2000.

TEWATIA, B.S.; BHATIA, S.K. Comparative ruminal biochemical and digestion related physiological characteristics in buffaloes and cattle fed a fibrous diet. Buffalo Journal, v.14, n.2, p.161$170,1998$.

UNIVERSIDADE FEDERAL DE VIÇOSA - UFV. Sistema de análise estatística e genética (SAEG). versão 8.0. Viçosa, MG: Universidade Federal de Viçosa, 1998.

Van KEULEN, J.; YOUNG, B.A. Evaluation of acid-insoluble ash as a marker in ruminant digestibility studies. Journal of Animal Science, v.44, n.2, p.283-287, 1977.

Van NEVEL, C.J. Modification of rumen fermentation by the use of additives. In: JOUANY, J.P. (Ed.) Rumen microbial metabolism and ruminant digestion. Paris: INRA, 1991. p.263-280.

Van NEVEL, C.J.; DEMEYER, D.I. Manipulation of rumen fermentation. In: HOBSON, P.N. (Ed.) The rumen microbial ecosystem. London: Elsevier Applied Science, 1988. p.387-443.

Van SOEST, P.J. Nutritional ecology of the ruminant. 2.ed. London: Cornell University Press, 1994. 476p.

Van SOEST, P.J.; ROBERTSON, J.B.; LEWIS, B.A. Methods for dietary fiber, neutral detergent fiber, and nonstarch polysaccharides in relation to animal nutrition. Journal of Dairy Science, v.74, n.12, p.3583-3597, 1991.

WALLACE, R.J. Manipulation of rumen function: ionophores, yeast culture and biotechnology. Biotechnology in the Feed Industry, v.37, n.1, p.193-203, 1992.

ZEOULA, L.M.; CALDAS NETO, S.F. Recentes avanços em amido na nutrição de vacas leiteiras. In: SIMPÓSIO INTERNACIONAL EM BOVINOCULTURA DE LEITE, 2001, Lavras. Anais... Lavras: Universidade Federal de Lavras, 2001. p.249-284. 